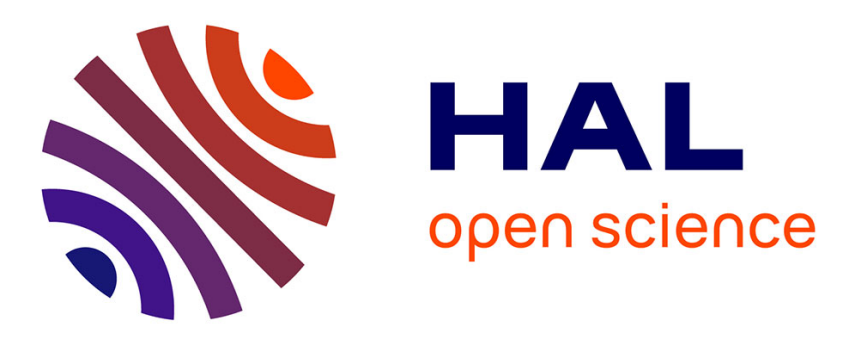

\title{
Comparing fitness measures and the influence of age of first reproduction in Columbian ground squirrels
}

\author{
Kristin Rubach, F Stephen Dobson, Bertram Zinner, Jan Murie, Vincent
}

Viblanc

\section{- To cite this version:}

Kristin Rubach, F Stephen Dobson, Bertram Zinner, Jan Murie, Vincent Viblanc. Comparing fitness measures and the influence of age of first reproduction in Columbian ground squirrels. Journal of Mammalogy, 2020, 10.1093/jmammal/gyaa086 . hal-02916845

\section{HAL Id: hal-02916845 \\ https://hal.science/hal-02916845}

Submitted on 30 Sep 2020

HAL is a multi-disciplinary open access archive for the deposit and dissemination of scientific research documents, whether they are published or not. The documents may come from teaching and research institutions in France or abroad, or from public or private research centers.
L'archive ouverte pluridisciplinaire $\mathbf{H A L}$, est destinée au dépôt et à la diffusion de documents scientifiques de niveau recherche, publiés ou non, émanant des établissements d'enseignement et de recherche français ou étrangers, des laboratoires publics ou privés. 


\section{Comparing fitness measures and the influence of age of first}

\section{2 reproduction in Columbian ground squirrels}

3

4

5 Kristin K. Rubach, F. Stephen Dobson*, Bertram Zinner, Jan O. Murie, And

6 VINCENT A. VIBLANC

7

8

9 Department of Biological Sciences, Auburn University, Auburn, AL 36849, USA (KKR,

$10 \quad F S D)$

11 Université de Strasbourg, Centre National de la Recherche Scientifique, Institut

12 Pluridisciplinaire Hubert Curien, Unité Mixte de Recherche 7178, 67087 Strasbourg,

13 France (FSD, VAV)

14 University of Strasbourg Institute of Advanced Sciences (USIAS), 67083 Strasbourg,

15 France (FSD)

16 Department of Mathematics and Statistics, Auburn University, Auburn, AL 36849, USA

$17 \quad(B Z)$

18 Department of Biological Sciences, University of Alberta, Edmonton, Alberta T6G 2E9,

19 Canada (JOM)

20

21

22

23 *Correspondant: fsdobson@msn.com 
The timing of life-history traits may have strong influences on the evolution of

25 lifecycles and on population demography. This is especially true of the age at

26 which females first reproduce (Cole's principle). We examined whether the age

27 at which females first reproduce influences fitness in Columbian ground squirrels,

28 for which females varied in the age at which they initially produce weaned

29 offspring, from ages 1 through 5 years. With 148 females with complete known

30 lifespans in a 28-year data set, we examined four fitness measures: individual

31 fitness $\left(\lambda_{\text {ind }}\right)$, individual fitness relative to the pattern of growth of the population

$32\left(\lambda_{r e l}\right)$, lifetime reproductive success (LRS), and LRS relative to the total LRS for

33 each female's cohort $\left(\mathrm{LRS}_{\text {rel }}\right)$. These metrics were calculated for offspring

34 produced at the time of weaning and offspring that survived to emerge after their

35 first hibernation period. Individual fitness $\left(\lambda_{\text {ind }}\right)$ was significantly associated

36 with population growth during a female's lifetime $\left(\lambda_{\text {Leslie }}\right)\left(\mathrm{R}^{2}=0.523, P<\right.$

37 0.0001); indicating the need to adjust individual fitness for demonstrated changes

38 in population growth and thus producing a relative individual fitness index $\left(\lambda_{\text {rel }}\right)$.

39 We regressed $\lambda_{\text {rel }}$ on age at first reproduction, and found significant selection

40 favoring earlier reproductive success $\left(\beta \pm \mathrm{SE}=-0.20 \pm 0.06 ; \mathrm{R}^{2}=0.306, P<\right.$

41 0.0001). When using an earlier (offspring at weaning) versus later (those that

42 survived their first hibernation) measure of fecundity, we found that the latter

43 introduced considerable variation, likely environmental, into the estimate of

44 selection. This greatly weakened the regression of relative fitness on the age at

45 first successful reproduction. LRS and $\mathrm{LRS}_{\text {rel }}$ exhibited non-significant changes

46 with age at first reproduction. Finally, those females that reproduced successfully 
at younger ages had similar litter sizes but significantly shorter lifespans than

females that matured when older, perhaps reflecting costs to early reproduction.

50 Key Words: age at first reproduction, Columbian ground squirrels, individual fitness,

51 Leslie matrix, lifetime reproductive success

54 As the size of populations change, demography must change as well (Caswell 1989,

55 2001; Oli, Slade, \& Dobson 2001; Dobson and Oli 2001, 2008). Demography is

56 composed of life-history traits, including age at first reproduction, survival, and the

57 magnitude of reproduction at different ages. Life-history traits may evolve, and they can

58 have a strong impact on fitness. Thus, life-history traits are often termed "fitness traits"

59 (e.g., Roff 1996; Merila and Sheldon 2000; Kosova et al. 2010). One life-history trait in

60 particular, the age at which reproduction begins, should be under strong selection to be as

61 early as possible (Cole 1954; Lewontin 1965; Meats 1971; Charnov and Schaffer 1973;

62 Bell 1976, 1980; Sibly and Calow 1986). In iteroparous mammals, however, numerous

63 factors (e.g., the quality or quantity of resources) might cause a delay in reproduction,

64 potentially resulting in fitness declines. In growing populations, individuals are thought

65 to have abundant resources and thus females may begin to reproduce earlier in their

66 lifetimes (Stearns 1992). On the contrary, in declining populations individuals are

67 assumed to have fewer resources, resulting in their devoting more energy to survival and

68 perhaps delaying their first reproduction to a later age. In either case, these expectations

69 might depend on the study species and the choice of fitness measure. 
In selecting a fitness measure, it is important to remember that what is being

71 estimated is the fitness of traits, in our case a female's age at first reproduction. The

72 relevant comparison is then among females that display alternative forms of the trait, as

73 estimates of the fitness of the trait forms. Lifetime reproductive success (LRS) is a

74 widely used fitness measure, defined as the number of offspring produced over a lifetime

75 (after Grafen 1988; examples in Clutton-Brock 1988; Merilä and Sheldon 2000; Jensen et

76 al. 2004; Descamps et al. 2006; McLoughlin et al. 2007). LRS, however, does not

77 account for the timing of reproduction during the lifecycle, which can have a significant

78 influence on the estimation of fitness (Cole 1954; Lewontin 1965; Roff 1992; Stearns

79 1992; Brommer et al. 2002).

80 Another suggested measure of trait fitness, developed by McGraw and Caswell

81 (1996) and termed "individual fitness", was patterned on the Leslie (1945) projection

82 matrix that describes population growth. Individual fitness encompasses an individual's

83 life history parameters over its lifetime, to produce a growth rate similar to that for

84 populations (termed lambda, $\lambda$ ). Use of this method to estimate fitness assumes that a

85 population of individuals similar in genotype would produce the same lambda value as

86 the individual under study. For example, individual fitness can be estimated for

87 individuals that carry a specific life history trait (i.e., age at first successful reproduction).

88 A lambda value is estimated for each individual that expresses an alternative form of the

89 life history trait, and a mean and variance are calculated for individual fitness of the

90 different trait forms. Previous studies have used LRS and individual fitness to estimate

91 selection on age at maturity, and these two methods often produced very different results

92 (e.g., McGraw and Caswell 1996; Brommer et al. 2002; Oli et al. 2002). Thus, the 
93 efficacy of either method has been questioned (e.g., Brommer et al. 2004; Reid et al.

94 2019), and a unified definition of fitness is lacking (Sæther and Engen 2015).

95 The individual fitness measure of McGraw and Caswell (1996), however, does

96 not give the context of the fitness values of other females in the population, and it is

97 against this larger group of females that an individual female's fitness should be

98 compared. In an increasing population, average fitness is greater than 1.0, and in a

99 decreasing population, less than 1.0. So, a female with individual fitness equal to 1.0

100 could be below or above average, respectively, depending on the mean fitness in the

101 population. During the lifespan of a particular female, mean fitness in the population can

102 be estimated from the growth rate of all co-occurring females, during the years of that

103 female's reproductive life, since the estimate is the result of reproduction and survival of

104 all of the females. By comparing individual fitness to population growth rate during a

105 female's lifetime, a relative measure of how the individual compares to the contemporary

106 population can be obtained. Such an adjusted individual fitness value (i.e., relative

107 individual fitness) can be compared among individuals that express alternative trait forms,

108 and used in a comparative evaluation of the selective advantage of age at first

109 reproduction.

110 Alternative methods of estimating fitness have been used to examine reproduction

111 in long-term studies of marmotine rodents. For instance, Neuhaus et al. (2004) concluded

112 that female Columbian ground squirrels (Urocitellus columbianus) match their

113 reproductive output with environmental circumstances. With fewer individuals,

114 resources were less limiting, leading to better body condition, greater survival and earlier

115 reproduction. Even so, reproductive success of females that first reproduced at ages 2 
116 and 3 were not significantly different. However, this study was based on a relatively

117 small sample size and used the LRS approach that does not adjust for population changes

118 or the timing of reproduction during the life cycle when estimating fitness. Using a

119 matrix estimate of individual fitness, Oli and Armitage $(2003,2008)$ found that selection

120 favored early maturity in Yellow-bellied marmots (Marmota flaviventris). However, they

121 did not adjust their fitness estimates for fluctuations in population size. It would thus be

122 interesting to compare such results to those obtained using alternative fitness evaluation

123 methods that account for the timing of breeding schedules and changes in population size.

124 Here, we used 28 years of longitudinal monitoring of a Columbian ground

125 squirrel population to establish the entire life cycles (from birth to death) of 148 females.

126 Our purpose was four-fold. First, we examined whether earlier age at first successful

127 reproduction led to increased fitness ("Cole's prediction", see Oli and Dobson 2003) for

128 female Columbian ground squirrels. We investigated whether the influence of age at first

129 reproduction on individual fitness changed with population growth. We predicted that

130 individual fitness would be greater for those females that began reproducing earlier,

131 particularly in years of increasing population growth rate, when resources should have

132 been most abundant (Dobson and Kjelgaard 1985a, 1985b). Alternatively, under limited

133 resources most likely associated with years of declining population growth, mean

134 individual fitness for females should be lower, but should remain relatively high for those

135 that reproduce earlier (i.e., above average compared to females reproducing later under

136 similar conditions of population growth).

137 Second, we compared LRS and relative fitness, that is individual fitness adjusted

138 for population growth, in order to evaluate similarities and differences between them. 
139 Third, we regressed relative fitness on the trait (viz., age at first reproduction) to test for

140 the presence of a selection differential (Lande and Arnold 1983; Arnold and Wade

141 1984b). We focused our analyses on two periods at which reproductive success could be

142 measured, near the time of weaning and when young survived to emerge from their first

143 hibernation season. We also conducted these analyses for relative individual fitness and

144 an index of relative LRS (LRS $\left.{ }_{\text {rel }}\right)$ that was based on the lifetime success of the cohort into

145 which a female was born. In our fourth and final set of analyses, we compared litter size

146 and longevity for females that first reproduced at different ages, to test for possible

147 tradeoffs between reproduction and survival for females that began investing in

148 reproduction at different points in their lifecycle.

\section{Materials AND MethodS}

151 Study species. - We studied a colony of Columbian ground squirrels in a montane

152 meadow at the Sheep River Provincial Park, Alberta, Canada (50³8’ N, $114^{\circ} 39^{`} \mathrm{~W}$,

153 elevation $1,550 \mathrm{~m}$ ). This population was monitored from 1992 to 2019 . Population size

154 for females $\geq 1$ year old fluctuated between 14 and 77, with a mean of 38 (Fig. 1).

155 Squirrels were caught with live traps (Tomahawk Live Trap Co., Tomahawk, WI, USA,

$15615 \times 15 \times 48 \mathrm{~cm}^{3}$ and $13 \times 13 \times 40 \mathrm{~cm}^{3}$ ) baited with a small amount of peanut butter. All

157 squirrels were trapped in the spring, within about three days of emergence from

158 hibernation, and weighed to the nearest $5 \mathrm{~g}$ with a Pesola spring scale (Pesola Ag, Baar,

159 Switzerland). Each ground squirrel was given a pair of uniquely numbered ear tags

160 (National Band and Tag Company, Newport, KY, US; Monel metal tag \# 1) and an

161 individually distinctive black mark on their back using black hair dye (Clairol 
162 Corporation, Stamford, CT, USA). Above ground activity of squirrels was easily

163 observed using binoculars from $3 \mathrm{~m}$ tall wooden observation benches that were dispersed

164 throughout the study site.

165 Columbian ground squirrels are medium sized (adults were typically 300-600 g at

166 emergence from hibernation) diurnal rodents that hibernate for approximately eight to

167 nine months of the year (Dobson and Murie 1987; Dobson et al. 1992). At our study site,

168 squirrels became active above ground in mid- to late April and remained active until late

169 July to mid-August. Within a week of emergence from hibernation, female ground

170 squirrels copulated with males on a single day, usually in underground consortships

171 (Murie 1995; Raveh et al. 2010, 2011). After about 24 days of gestation and 27 days of

172 lactation, pups emerged above ground for the first time from the single-entrance nest

173 burrow that was maintained by the mother (Murie and Harris 1982). Newly emerged

174 pups were caught, weighed to the nearest gram, and uniquely marked. Subsequent

175 observations of the complete litter ensured that we captured all young at the time of

176 emergence, which coincided with the process of weaning. Mothers were trapped and

177 examined at the same time that weaned young were caught, to ensure that they had

178 lactated. Thus, both maternal association and weaned litter size were accurately

179 measured.

180

$181 \quad$ Population census. - We conducted a modified post-breeding census using the

182 long-term data set on female Columbian ground squirrels (after Dobson and Oli 2001).

183 In a post-breeding census, each individual is counted just after annual reproduction. We

184 estimated survival from emergence in one spring to the next, since residents from the 
185 previous year remain in the spring populations. Further, the dispersal period, usually of

186 younger males, occurs later in the active season at about the time of weaning (Wiggett

187 and Boag 1989). Spring populations best reflected the individuals that were residents in

188 the population, as indicated by having hibernated in the study colony. The number of

189 weaned young that emerged from nest burrows at the end of the lactation period or that

190 survived to emerge from hibernation in the next spring were used to measure

191 reproduction.

192 For 148 females, we constructed individual age-specific matrices that varied in

193 size (1-14 years; average 4.70 years). For each matrix, we estimated individual fitness

194 (see below), using the individual fitness approach (after McGraw and Caswell 1996; Oli

195 and Armitage 2003, 2008; Viblanc et al. 2010; Dobson et al. 2012). Age at first

196 reproduction was defined as the first time a female successfully weaned a litter. Some

197 females produced weaned litters for the first time when they were yearlings (1-year-old,

$198 \mathrm{~N}=13)$. Most females weaned their first litter at age $2(\mathrm{~N}=96)$, and occasionally a

199 female's initial weaning success was prolonged to 3-years-old $(\mathrm{N}=30)$, 4-years-old $(\mathrm{N}=$

200 8), and 5-years-old ( $\mathrm{N}=1)$. For some analyses we combined the last three groups of

201 mothers into a category of 3 years of and older.

202

203 Fitness analyses. - The fitness of females that first bred at different ages was

204 estimated using four fitness measures: LRS, LRS relative to the total LRS of the

205 female's cohort, individual fitness $\left(\lambda_{\text {ind }}\right)$, and relative individual fitness (adjusted for

206 population growth, $\left.\lambda_{\text {rel }}\right)$. 
208 calculated LRS by simply adding up the number of offspring that were weaned over a

209 female's lifetime. To estimate LRS of individual females relative to their peers, we

210 regressed LRS on the total LRS of the cohort of females into which each individual

211 female was born, and used the residual as the estimate of her relative lifetime success

212 (LRS $\left.\mathrm{Lel}_{\mathrm{rel}}\right)$. This method avoided the use of ratios, which have statistical shortcomings

213 (Hinkley 1969). For this analysis, only 132 females were included, because only

214 complete cohorts were used (number of years $=20$, females born in 1991-2010).

215 Individual fitness $\left(\lambda_{\text {ind }}\right)$ and cohort fitness $\left(\lambda_{\text {Leslie }}\right)$ : To obtain $\lambda_{\text {rel }}$, we estimated

216 both individual fitness (McGraw and Caswell 1996) and population growth rate for each

217 female's cohort during her lifetime. Both of these were modifications of the population

218 growth projection matrix developed by Leslie (1945). Briefly, an example of the Leslie

219 matrix approach for a post-breeding population census is:

220

$$
\left[\begin{array}{cccc}
F_{0} & F_{1} & F_{2} & 0 \\
S_{0} & 0 & 0 & 0 \\
0 & S_{1} & 0 & 0 \\
0 & 0 & S_{2} & 0
\end{array}\right]\left[\begin{array}{c}
N_{0, t} \\
N_{1, t} \\
N_{2, t} \\
N_{3, t}
\end{array}\right]=\left[\begin{array}{c}
N_{0, t+1} \\
N_{1, t+1} \\
N_{2, t+1} \\
N_{3, t+1}
\end{array}\right]
$$

222 Subset $0,1,2$, and 3 are age groups, and $t$ and $t+1$ are time periods. Average fertility is

223 across the top row of the matrix, and is defined as:

$$
F_{\mathrm{x}}=S_{\mathrm{x}} * \mathrm{~m}_{\mathrm{x}+1} * 0.5
$$

$225 S_{\mathrm{x}}$ is the survival rate, calculated as the proportion of females that survive from year $\mathrm{x}$ to

226 year $x+1$. Fecundity, $\mathrm{m}_{\mathrm{x}+1}$, is defined the mean number of offspring at age $\mathrm{x}+1$. Since

227 the analysis is only for the female part of the population, $\mathrm{m}_{\mathrm{x}+1}$ is multiplied by a half 
228 (Dobson and Oli 2001). In the case of Columbian ground squirrels, we estimated

229 fecundity in two ways; either using half the size of litters at weaning, or using half the

230 young that survived to be 1 year old in the subsequent year (viz., half the number of

231 surviving yearlings). We used both reproductive output measures to test for similarity in

232 fitness patterns, and expected that the latter measure would reflect more closely those

233 surviving to reproductive age, perhaps a better fitness measure (Brommer et al. 2002).

234 The last column represents the year that the female died; hence it is comprised of zeros.

235 The Leslie projection matrix represents age structured information about reproduction

236 and survival for a population. The dominant right eigenvector of this matrix is the finite

237 growth rate of the population, usually called lambda $(\sqrt{\lambda})$.

238 Based on McGraw and Caswell (1996), we modified the above population growth

239 matrix to calculate the growth of a specific genotype based on the reproduction and

240 survival of an individual female. In this case, the formulation of the matrix becomes:

$$
\left[\begin{array}{cccc}
F_{0} & F_{1} & F_{2} & 0 \\
1 & 0 & 0 & 0 \\
0 & 1 & 0 & 0 \\
0 & 0 & 1 & 0
\end{array}\right]
$$

242 The top row of the individual matrix is calculated as above by multiplying survival by

243 fecundity, $\mathrm{m}_{\mathrm{x}+1}$, and by one half for an individual female. Survival is binary, however, 1

244 in the years in which the female lived, zero otherwise. Litter size at each age is used for 245 fecundity, or as above the number of offspring that survive to become yearlings. In this

246 case, the dominant right eigenvalue is the population growth rate for a given genotype, as

247 estimated for a single female, and individual females are then averaged to yield the mean 
248 estimate of fitness of the trait form. The dominant right eigenvalue is the individual

249 fitness measure, $\lambda_{i n d}$. These matrices have different dimension (are of different size) for

250 different females, because individual lifespans vary.

251 We adjusted individual fitness $\left(\lambda_{\text {ind }}\right)$ for changes in population size (i.e., periods

252 of increases and decreases in size as estimated by population "growth") by constructing a

253 Leslie (1945) projection matrix for the specific years of each individual female's lifetime

$254\left(\lambda_{\text {Leslie }}\right)$. These estimates were then used to typify mean fitness during the female's

255 lifetime. Using the notation for the modified Leslie matrix above, $S_{\mathrm{x}}$ was thus the

256 survival from year $\mathrm{x}$ to year $\mathrm{x}+1$ for all females in the female's cohort, as in the typical

257 Leslie matrix, and $m_{x}$ was the mean litter size for all of the adult females of age $x$. For

258 example, $S_{1}$, was the mean survival of all females between the ages of 1 and 2 , when the

259 individual female under examination was age 1 and then 2 . Another example, $\mathrm{m}_{2}$ was the

260 mean litter size of all females that were age 2 in the year that the individual female was

261 age 2. Individual fitness values $\left(\lambda_{\text {ind }}\right)$ were regressed on the resulting modified Leslie

262 matrix estimate of lambda $\left(\lambda_{\text {Leslie }}\right)$, to produce residuals that represented individual

263 fitness adjusted for population growth during her lifetime. These residuals were added to

264 one to yield adjusted lambda for the Leslie matrix $\left(\lambda_{\text {rel }}\right)$, since lambda of 1.0 represents

265 non-growing populations in population ecology (e.g., Stearns 1992). This method is

266 similar to that used by Viblanc et al. (2010) and Dobson et al. (2012), but those studies

267 used changes in population size and the individual fitness matrix in place of our use of

268 the modified Leslie matrix to estimate population growth. In comparison to changes in

269 population size, the modified Leslie matrix is based on a female's cohort and takes actual

270 survival patterns into account. 
272 at first reproduction, if the population were increasing or decreasing. To test this

273 possibility, we regressed individual lambda $\left(\lambda_{\text {ind }}\right.$, the dependent variable) on our

274 modified Leslie matrix (viz., population growth during the lifetime of the reproductive

275 adult females, $\lambda_{\text {Leslie }}$, the independent variable), made age at first reproduction a

276 covariate, and included the interaction between $\lambda_{\text {Leslie }}$ and age at first reproduction. For

277 this analysis, we pooled females that first reproduced at age three and above, because the

278 oldest females were limited in sample size.

Selection analyses. - To determine if there was directional selection for age at first

281 reproduction, we regressed relative fitness $\left(\lambda_{\text {rel }}\right)$ and separately $\mathrm{LRS}_{\text {rel }}$ on age at first

282 successful reproduction (Lande and Arnold 1983; Arnold and Wade 1984a, 1984b). The

283 sign of the coefficient $(\beta)$ indicates the direction of selection. We also used a quadratic

284 regression to estimate stabilizing selection $(\gamma)$ as evidenced by significant regression

285 coefficients. Significant directional or stabilizing selection on age at first reproduction

286 occurs when $\beta$ and $\gamma$ are significantly different from 0 (Lande and Arnold 1983; McGraw

287 and Caswell 1996).

289 Statistics. - We used the statistical program R (version 3.5.2, 2018) to analyze

290 matrices and calculate lambda (scripts available on request). Differences among age at

291 first reproduction, lambda, population growth, and LRS were tested using linear models.

292 For significant differences among ages at first reproduction, Tukey's honest significant

293 differences (HSD) tests for multiple comparisons were used. Means were given with 
294 standard errors, and Hedges g was used to estimate effect sizes.

\section{RESUltS}

298 We regressed individual fitness $\left(\lambda_{\text {ind }}\right)$ on the rate of population growth $\left(\lambda_{\text {Leslie }}\right)$, both

299 calculated over the lives of individual mothers. We included age at first reproduction as a

300 covariate (ages 1,2, and 3 and above;), and found no significant interaction between age

301 at first reproduction and population growth (Fig. 2a, overall model $\mathrm{R}^{2}=0.523, \mathrm{~F}=52.6$,

$302 \mathrm{df}=3,144, P<0.0001$; interaction $\beta=-0.063 \pm 0.087, \mathrm{df}=1,144, \mathrm{t}=-0.72, P=0.47)$.

303 For females that first reproduced as yearlings, 2-year olds, and 3+ year olds, the estimate

304 of individual fitness changed in a similar rate as population growth rate increased (Table

$3051)$.

306 We then used the number of yearlings that survived to emerge from hibernation in

307 the following spring to estimate offspring production by individual mothers and again

308 regressed individual fitness $\left(\lambda_{\text {indY }}\right)$ on the rate of population growth $\left(\lambda_{\text {Leslie }}\right)$, accounting

309 for age at first reproduction as a covariate (ages 1, 2, and 3 and above), and found no

310 significant interaction between age at first reproduction and population growth (Fig. 2b,

311 overall model $\mathrm{R}^{2}=0.419, \mathrm{~F}=34.6, \mathrm{df}=3,144, P<0.0001$; interaction $\beta=-0.005 \pm$

$3120.185, \mathrm{df}=1,144, \mathrm{t}=-0.03, P=0.98)$. For females that first reproduced as yearlings, 2 -

313 year olds, and $3+$ year olds, this estimate of individual fitness changed in a similar rate as

314 population growth rate increased (Table 1). 
317 numbers of weaned offspring to measure fecundity, relative individual fitness was

318 significantly different among females that first reproduced at different ages (Fig. 3a, $R^{2}=$

$3190.309, \mathrm{~F}=65.3, \mathrm{df}=1,146, P<0.0001)$. Post-hoc Tukey tests revealed that each age

320 group (for ages 1, 2, and 3 and above) were significantly different from the others (all $\mathrm{P}<$

321 0.0001). Effect sizes of the comparisons were all large and highly significant (Hedges $g$

322 and $95 \%$ CI: ages 1 vs. $2=1.63_{[1.01-2.25]} ; 1$ vs. $3+=2.34_{[1.56-3.11]} ; 2 v s .3+=1.01_{[0.61-}$

$3231.40]$ ).

324 Using the numbers of surviving yearling offspring to measure fecundity, relative

325 individual fitness $\left(\lambda_{\text {relY }}\right)$ was not quite significantly different among females that first

326 reproduced at different ages (Fig. $3 \mathrm{~b}, \mathrm{R}^{2}=0.022, \mathrm{~F}=3.27$, $\mathrm{df}=1,146, P=0.07$ ). Post-

327 hoc Tukey tests revealed that each age group (ages 1,2, and 3 and above) was not

328 significantly different from the others $(0.18<\mathrm{P}<0.48)$. Effect sizes of the comparisons

329 were small to medium (Hedges $g$ and $95 \%$ CI: $\alpha$ at 1 vs. $2=0.34_{[-0.24-0.92]} ; 1 v s .=0.61_{[-}$

$\left.330 \quad 0.04-1.25] ; 2 v s .3+=0.22_{[-0.16-0.59]}\right)$.

Age at first reproduction in relation to LRS and $L R S_{\text {rel. }}$ - Similar analysis of LRS

333 among mothers that first reproduced at different ages were not significant (Fig. 3c; $\mathrm{R}^{2}=$

$3340.001, \mathrm{~F}=0.20, \mathrm{df}=1,146, P=0.65)$. Post-hoc Tukey tests revealed that each age group

335 ( $\alpha=1,2$, and 3 and above) was not significantly different from the others $(0.77<\mathrm{P}<$

336 0.98). Effect sizes of the comparisons were small or negligible (Hedges g and 95\% CI;

337 ages 1 vs. $2=-0.07_{[-0.65-0.51]}, 1$ vs. $\left.3+=0.06_{[-0.57-0.70]}, 2 v s .3+=0.13_{[-0.25-0.50]}\right)$. LRSY

338 (lifetime reproductive success measured by surviving yearling offspring) among mothers 
339 that first reproduced at different ages was not significant (Fig. $3 \mathrm{~d} ; \mathrm{R}^{2}=0.005, \mathrm{~F}=0.67$,

$340 \mathrm{df}=1,146, P=0.41)$. Post-hoc Tukey tests revealed that each age group (ages 1,2 , and 3

341 and above) was not significantly different from the others $(0.72<\mathrm{P}<0.98)$. Estimates of

342 the effect sizes of the comparisons were small to negligible (Hedges g and 95\% CI: ages

3431 vs. $2=0.05_{[-0.53-0.64]} ; 1$ vs. $\left.3+=0.24_{[-0.40-0.87]} ; 2 v s .3+=0.15_{[-0.23-0.52]}\right)$.

$344 \quad$ Analyses of $\mathrm{LRS}_{\text {rel }}$ among mothers that first reproduced at different ages were not

345 significant $\left(\mathrm{R}^{2}=0.001, \mathrm{~F}=0.19, \mathrm{df}=1,130, P=0.67\right)$. Post-hoc Tukey tests revealed

346 that each age group (ages 1,2, and 3 and above) was not significantly different from the

347 others $(0.74<\mathrm{P}<1.00)$. Effect sizes of the comparisons were all negligible (Hedges $\mathrm{g}$

348 and $95 \% \mathrm{CI}$; ages 1 vs. $2=0.13_{[-0.51-0.76]}, 1$ vs.3+= $=0.03_{[-0.71-0.65]}, 2$ vs. $3+=0.14_{[-0.54-}$

$3490.28]$ ). Similar analyses using the number of surviving yearling offspring to calculate

350 relative $\operatorname{LRS}\left(\mathrm{LRS}_{\text {relY }}\right)$ were also not significant $\left(\mathrm{R}^{2}=0.000, \mathrm{~F}=0.01, \mathrm{df}=1,130, P=\right.$

351 0.92). Post-hoc Tukey tests showed that the age groups (ages 1, 2, and 3 and above) were

352 not significantly different in $\operatorname{LRS}_{\text {relY }}(0.99<\mathrm{P}<1.00)$. Finally, effect sizes of the

353 comparisons were all negligible (Hedges g and 95\% CI; ages $1 v s .2=0.03_{[-0.60-0.66]}, 1$

$\left.354 v s .3+=0.04_{[-0.64-0.72]}, 2 v s .3+=0.01_{[-0.38-0.40]}\right)$.

Selection analyses on age at first reproduction. - Linear regression of fitness

357 adjusted for population growth $\left(\lambda_{\text {rel }}\right.$, based on numbers of weaned offspring) on age at

358 first reproduction (here varying between 1 and 5) suggested directional selection for early

359 age at first reproduction (Fig. $4 \mathrm{a} ; \beta \pm \mathrm{SE}=-0.20 \pm 0.06 ; \mathrm{R}^{2}=0.306, \mathrm{~F}=64.2, \mathrm{df}=1,146$,

$360 P<0.0001)$. Slight but significant disruptive selection was also evident by quadratic

361 regression $\left(\gamma \pm \mathrm{SE}, 0.05 \pm 0.02, P=0.01\right.$; overall $\mathrm{R}^{2}=0.335, \mathrm{~F}=36.5, \mathrm{df}=2,145, P<$ 
362 0.0001). A similar analysis using $\mathrm{LRS}_{\text {rel }}$ as a fitness measure regressed on age at first

363 reproduction was not significant $\left(\beta \pm \mathrm{SE}=-0.59 \pm 0.75 ; \mathrm{R}^{2}=0.005, \mathrm{~F}=0.62, \mathrm{df}=1,130\right.$,

$364 P=0.43)$, nor was evidence of stabilizing selection significant $(\gamma \pm \mathrm{SE},-0.29 \pm 0.65, P=$

3650.66 ; overall $\left.\mathrm{R}^{2}=0.006, \mathrm{~F}=0.40, \mathrm{df}=2,129, P=0.67\right)$. When fitness was based on

366 surviving yearling offspring $\left(\lambda_{\text {relY }}\right)$, linear regression of relative fitness on age at first

367 reproduction only approached significance, but revealed a similar pattern to $\lambda_{\text {rel }}$ (Fig. 4b;

$\left.368 \beta \pm \mathrm{SE}=-0.08 \pm 0.05 ; \mathrm{R}^{2}=0.022, \mathrm{~F}=3.25, \mathrm{df}=1,146, P=0.07\right)$, and evidence of

369 disruptive selection was trivial $\left(\gamma \pm \mathrm{SE}, 0.02 \pm 0.04, P=0.59\right.$; overall $\mathrm{R}^{2}=0.024, \mathrm{~F}=$

$3701.77, \mathrm{df}=2,145, P=0.17)$. A similar analysis using $\mathrm{LRS}_{\mathrm{relY}}$ as a fitness measure was not

371 significant $\left(\beta \pm \mathrm{SE}=-0.48 \pm 0.40 ; \mathrm{R}^{2}=0.011, \mathrm{~F}=1.44, \mathrm{df}=1,130, P=0.23\right)$, and

372 evidence of stabilizing selection was trivial $\left(\gamma \pm \mathrm{SE},-0.11 \pm 0.35, P=0.74\right.$; overall $\mathrm{R}^{2}=$

$3730.012, \mathrm{~F}=0.77, \mathrm{df}=2,129, P=0.47)$.

374

375

Testing for a trade-off and the cost of reproduction. - We examined litter sizes for

376 females that first reproduced at ages 1, 2, and 3 and above. There were no significant

377 differences in mean litter sizes among females in the year in which they first reproduced

378 (Table 2). There were also no significant differences in mean number of yearling

379 offspring produced from their first litter when females first reproduced at different ages

380 (Table 2). Finally, we examined the length of life for females that first reproduced at

381 ages 1, 2, and 3 and above. Length of life increased significantly for females that

382 matured later in life (Table 2). Post-hoc Tukey tests indicated that this was significant

383 only when comparing females that matured at 2 , and 3 and above $(1$ vs. $2, P=0.86 ; 1$

$384 v s .3+, P=0.10 ; 2 v s .3+, P=0.02)$, but the effect sizes of all comparisons were relatively 
385 large (Hedges g and 95\% CI: $\alpha$ at 1 vs. $2=1.60_{[1.32-1.89]} ; 1$ vs. $3+=1.48_{[1.13-1.83]} ; 2 v s .3+$

$\left.386=2.02_{[1.73-2.30]}\right)$.

\section{DISCUSSION}

389 Among life-history traits, reproduction and survival have received substantial

390 research attention (e.g., Stearns 1992; Roff 1992). The timing of lifecycle events is also

391 important in the evolution of life-history tactics (e.g., Oli and Dobson 2003). For long-

392 lived species, events such as the age at which females begin to reproduce can have major

393 evolutionary influences on life-history patterns. Not surprisingly, age at first

394 reproduction can have a substantial influence on fitness, with fitness substantially

395 diminished by a late start to breeding (Bell 1976, 1980; especially in avian studies,

396 McGraw and Caswell 1996, Brommer et al. 2002, Oli et al. 2002). We asked whether

397 age at first reproduction made a significant difference to the fitness of individual female

398 Columbian ground squirrels.

399 To examine the importance of first reproducing at different ages to fitness, we

400 were faced with three problems; one was whether to adjust for population growth. It

401 seemed plausible that fitness should be measured differently in increasing versus

402 decreasing populations, considering that our population of Columbian ground squirrels

403 fluctuated substantially from year to year. The second problem was to determine which

404 of two possible techniques to apply to our question: the individual fitness approach of

405 McGraw and Caswell (1996) or the widely used LRS. The third problem was when to

406 measure offspring production. The end of intense period of maternal care (viz., gestation

407 and lactation) that occurs when young are weaned seems reasonable, at least for an initial 
408 examination. However, a better measure might be when those offspring become

409 surviving descendants that themselves reproduce (Boyce and Perrins 1987; Brommer et

410 al. 2004). Thus, we examined the production of yearlings, a subadult age class for most

411 individuals (but an age at which a few females successfully reproduce). We also made a

412 preliminary analysis of the strength of natural selection on the age of first reproduction

413 for a species in which it was variable. Finally, we examined litter size at first

414 reproduction and longevity for females that began reproduction at different ages, in a

415 preliminary test of the potential for tradeoffs of the age at which females began to

416 reproduce with initial reproduction or subsequent survival.

417 In years of population increase, mean fitness in a population will be relatively

418 higher, and conversely in years of population decline. Thus, it might be reasonable to

419 adjust fitness for changes in population size. We compared individual fitness $\left(\lambda_{\text {ind }}\right)$ to the

420 change in population size over the lifetimes of females using a Leslie matrix $\left(\lambda_{\text {Leslie }}\right)$.

421 This analysis tested whether individual fitness changes significantly with an estimate of

422 mean fitness (viz., population growth rate) during the lifetimes of individual females.

423 Both when using the number of weaned offspring and number of yearling offspring to

424 measure fecundity, we found significant differences in $\lambda_{\text {ind }}$ (and $\lambda_{\text {indY }}$ ) that were

425 associated with changes in population growth. This was true for females that first

426 reproduced at different ages, and for those females combined, regardless of which

427 measure of fecundity was used. Therefore, we recommend adjustment for population

428 growth ( $\lambda_{\text {rel }}$, see also Viblanc et al. 2010; Dobson et al. 2012).

429 Because LRS is rate insensitive (Brommer et al. 2002), there was no obvious way

430 to adjust LRS for population growth or decline. To compare reproductive success and 
431 estimate fitness relative to each female's peers, we regressed LRS for each female on the

432 total reproductive success of the cohort into which she was born, and used the residuals

433 of this analyses as an estimate of relative LRS. This estimate was based on the cohort

434 into which females were born, similar to the estimate of relative individual fitness.

435 Relative LRS, however, did not appear to yield additional insight to simply using LRS as

436 an estimate of fitness. Estimates of fitness are problematical, as estimates from

437 individual fitness and LRS, and estimates from descendants over an extended pedigree

438 may not closely agree (Brommer et al. 2004; Reid et al. 2019). In addition, the most

439 appropriate measures may depend on both changes in population density and on

440 environmental fluctuations (Sæther and Engen 2015). We accounted for changes in

441 population density among years for individual females by statistically comparing their

442 individual fitness to changes in population growth rate for their cohort.

443 Next, we compared $\lambda_{\text {rel }}$ and LRS for similarity of measures. Because $\lambda_{\text {rel }}$ is rate-

444 sensitive (sensu Brommer et al. 2002), we expected it to show a pattern of decline with

445 age at first reproduction, as in earlier studies (McGraw and Caswell 1996). Similar to

446 those previous results, and when number of offspring at weaning was used to measure

447 fecundity, $\lambda_{\text {rel }}$ declined significantly with age at first reproduction. A similar pattern was

448 found when yearling offspring were used to measure fecundity $\left(\lambda_{\text {relY }}\right)$, though it only

449 approached significance. It is likely that variation in survival introduced by the vagaries

450 of living in a fluctuating environment (with both ecological and social changes) rendered

451 the association between age at first reproduction and fitness weaker. If we were able to

452 track a suitable number of female offspring through their age at first reproduction, we

453 would expect the association with fitness to be even weaker. This phenomenon is 
454 particularly important because it is only offspring that survive to reproduce that can pass

455 on any genetic propensity for the trait form to future generations. Our conclusion is that

456 there is likely little or weak selective advantage to earlier onset of reproduction in

457 Columbian ground squirrels, if one measures fitness from those that are most likely to 458 contribute to future generations.

459 LRS (lifetime reproductive success) has been used as a measure of fitness in 460 many species (e.g., Clutton-Brock 1988; Newton 1989; Merilä and Sheldon 2000; Jensen

461 et al. 2004; Descamps et al. 2006; McLoughlin et al. 2007). LRS is limited by the fact

462 that it does not consider the timing of reproduction, which can have a significant

463 influence on the fitness of a trait group (Cole 1954; Lewontin 1965; Roff 1992; Stearns

464 1992). Females who mature later might have a similar LRS value to those maturing

465 earlier, if particular life-history traits exhibit tradeoffs (Brommer et al. 2002). LRS did

466 not show significant evidence of fitness advantage with respect to age at first

467 reproduction in our study, regardless of whether LRS was estimated from offspring near

468 the time of weaning or at their emergence from their first hibernation. These results

469 reflect similar findings in European sparrowhawks (Accipeter nisus; McGraw and

470 Caswell 1996), Ural owls (Strix uralensis; Brommer et al. 1998), and wood ducks (Aix

471 sponsa; Oli et al. 2002).

472 One might expect females that reproduce later in life to have lower LRS, because

473 each breeding season skipped is a missed chance to reproduce. However, if there were a

474 survival cost to reproduction at earlier ages (e.g., Williams 1966; Reznick 1985), that

475 pattern might be obscured in long-lived species. In any case, there were no significant

476 changes in LRS for female ground squirrels that matured at different ages, whether LRS 
477 was measured as weaned offspring or the production of yearling offspring. A slight

478 decline in LRS occurred for females that successfully weaned offspring at ages 3, 4, and

4795 , but this pattern was not significant, regardless of whether LRS was measured at

480 weaning or using the number of yearling offspring. Studies of allelic contributions to

481 future generations suggest that LRS and $\lambda_{\text {ind }}$ produce roughly comparable estimates of

482 long-term fitness measures, though such long-term allele measures require pedigrees that

483 include both males and females (Brommer et al. 2004; Reid et al. 2019). The apparent

484 paradox of differences in patterns of $\lambda_{\text {ind }}$ and LRS with respect to life event timing may

485 be that the seeming advantage of early reproduction degrades somewhat over time, with

486 the two measures becoming more similar as offspring are counted closer to when the

487 offspring themselves become reproductive adults. The pattern of difference between

488 individual fitness and LRS seemed to show a decrease over time in our population of

489 Columbian ground squirrels.

490 Our next goal was to quantify selection on age at first reproduction, by regressing

$491 \lambda_{\text {rel }}$ on age at first reproduction (the regression of relative fitness on the trait, after Lande

492 and Arnold 1983). When offspring were counted at weaning, there was significant

493 directional selection for reproducing earlier (see also McGraw and Caswell 1996).

494 Similar results were obtained for yellow-bellied marmots (Oli and Armitage 2003, 2008).

495 In our case, this was accompanied by significant, though very mild disruptive selection.

496 However, while disruptive selection favors extreme phenotypes, the main polynomial

497 influence on age at first reproduction was obtained from yearling females that had

498 somewhat greater success, on average, than expected from the linear model. A similar

499 pattern was evident when fecundity was measured from the number of surviving yearling 
500 offspring $\left(\lambda_{\text {relY }}\right)$, although it only approached significance and had a trivial effect size.

501 Measuring fecundity from yearling offspring caught at emergence from hibernation in the

502 next spring in the estimation of individual fitness likely introduced extrinsic variation in

503 our measure of selection. Such variation may be caused by differential offspring

504 mortality due to infanticide, predation, and overwinter mortality during hibernation (e.g.,

505 Murie and Boag 1984; Dobson 1990; Maron et al. 2010). Apparent fitness advantages

506 for trait forms that occur early in life, like age at first reproduction, may be diluted by the

507 time that the offspring themselves reproduce, and perhaps render natural selection on

508 such trait forms relatively trivial.

509 Brommer et al. (2002) suggested that individual fitness was only appropriate in

510 non-equilibrium populations, citing Stearn's (1992) book on life histories. The fitness of

511 alternative trait forms, however, is more at issue than the overall growth of the population.

512 Trait frequencies may change largely independently of changes in population growth,

513 despite the fact that both depend on reproduction, survival, and migration. Fitness

514 differences favor alternative trait forms, and the fitness of individuals is only a means of

515 estimating the fitness of trait forms. Thus, in an equilibrium population in terms of

516 population growth, a trait form may increase through a process akin to population growth

517 and eventually reach fixation. This is also true for changes in trait frequency in

518 populations, as most in nature, that exhibit nearly constant periods of increase (from

519 reproduction and immigration) and decrease (from mortality and emigration). This basic

520 concept has led to ideas about selection for traits associated with changes in the balance

521 of reproduction and survival in times of population change (Boyce and Perrins 1987). 
523 growth; after Dobson 1992), and those that were successful at reproducing had slightly

524 smaller litters than females that first produced offspring at older ages. This pattern was

525 not significant, nor were there any significant differences among these initial

526 reproductive efforts in yearling offspring production, though $1^{\text {st }}$-time breeders may have

527 slightly lower reproductive success than multiparous mothers (Neuhaus et al. 2004;

528 Broussard et al. 2008). Nonetheless, females that were reproducing for the first time had

529 comparable fecundity, on average, regardless of their age. There was a significant pattern

530 of greater length of life for females that began reproduction later in life; however, that

531 might reflect a cost of early commitment to reproductive adulthood. Trade-offs of

532 current reproduction and subsequent reproduction and survival have been termed the

533 “costs of reproduction” in life-history theory (e.g., Williams 1966; Reznick 1985).

534 Columbian ground squirrels appear to lack such a trade-off, at least phenotypically

535 (Murie and Dobson 1987; Hare and Murie 1992; Neuhaus 2000; Skibiel et al. 2013;

536 Rubach et al. 2016). Our results suggest that the age at which females first reproduce

537 might be a trait to consider when looking for potential life-history trade-offs.

\section{ACKNOWLEDGEMENTS}

540 We thank the many research assistants since 1992 for their contributions to the extended

541 data file. Animal care conformed to Auburn University IACUC protocols, most recently

542 \#2012-2051, 2015-2626, and 2018-3227 (also approved by: University of Calgary -

543 LESACC). M.K. Oli, M.E. Wolak, and an anonymous reviewer provided very helpful

544 comments on versions of the manuscript. Field research was funded in part by a Natural 
545 Sciences and Engineering Research Council of Canada grant to J.O. Murie and by a

546 National Science Foundation grant (DEB-0089473) to F.S. Dobson. We thank the

547 Biogeosciences Institute of the University of Calgary, Alberta, for housing and facilities

548 at the R.B. Millar Biological Station, Kananaskis Field Stations, especially K. Ruckstuhl

549 (faculty organizer and researcher at the R.B. Miller Field Station), J. Mappin-Buchannan

550 and A. Cunnings (Station Managers), and E. Johnson (Institute Director). Fieldwork was

551 carried out under permits from Alberta Sustainable Resource Development, and

552 supported by a CNRS Projet International de Coopération Scientifique (PICS-07143)

553 grant to V.A. Viblanc. F.S. Dobson thanks the Institute of Advanced Studies of the

554 University of Strasbourg for financial support through an USIAS fellowship, and the

555 Région Grand Est and the Eurométropole de Strasbourg for the award of a Gutenberg 556 Excellence Chair.

\section{Literature Cited}

559 ARNOLD, S.J., and M.J. WADE. 1984a. On the measurement of natural and sexual 560 selection: theory. Evolution 38:709-719.

561 ARNOLD, S.J., and M.J. WADE. 1984b. On the measurement of natural and sexual 562 selection: applications. Evolution 38:720-734.

563 BAtes, D., M. MAechler, B. Bolker, and S. WALKer. 2014. lme4: Linear mixed564 effects models using Eigen and S4_. R package version 1.1-7, http://CRAN.R $565 \quad$ project.org/package=lme4.

566 BELL, G. 1976. On breeding more than once. American Naturalist 110:57-77. 
567 BeLL, G. 1980. The costs of reproduction and their consequences. American Naturalist $568 \quad 116: 45-76$.

569 BoYCE, M.S., AND C.M. PERRINS. 1987. Optimizing great tit clutch size in a fluctuating $570 \quad$ environment. Ecology 68:42-153.

571 Brommer, J. E., H. PietiäInen, And H. Kolunen. 1998. The effect of age at first 572 breeding on Ural owl lifetime reproductive success and fitness under cyclic food 573 conditions. Journal of Animal Ecology 67:359-369.

574 BROMMER, J.E., J. MERILÄ, AND H. KOKKO. 2002. Reproductive timing and individual 575 fitness. Ecology Letters 5:802-810.

576 Brommer, J.E., L. Gustafsson, H. Pietiäinen, And J. Merilä. 2004. Single-

577 generation estimates of individual fitness as proxies for long-term genetic $578 \quad$ contribution. American Naturalist 164:505-517.

579 Broussard, D.R., F.S. Dobson, AND J.O. MurIE. 2008. Previous experience and 580 reproductive investment of female Columbian ground squirrels. Journal of 581 Mammalogy 89:145-152.

582 CASWell, H. 1989. The analysis of life table response experiments. I. Decomposition of 583 treatment effects on population growth rate. Ecological Modelling 46:221-237.

584 CASWELL, H. 2001. Matrix population models: construction, analysis, and 585 interpretation. Sinauer, Sunderland, Mass.

586 COLE, L.C. 1954. The population consequences of life history phenomena. Quarterly $587 \quad$ Review of Biology 29:103-137.

588 CHARNOV, E.L., AND W.M. SCHAFFER. 1973. Life history consequences of natural 589 selection: Cole's result revisited. American Naturalist 107:791-793. 
590 ClutTon-Brock, T.H. 1988. Reproductive Success. In: Reproductive Success (ed.

591 Clutton-Brock, T.H.). University of Chicago Press, Chicago, pp. 472-485.

592 Descamps, S., S. Boutin, D. Berteaux, AND J.-M. Gaillard. 2006. Red squirrels

593 trade a long life for an early reproduction. Proceedings of The Royal Society B,

$594 \quad$ Biological Sciences 273:2369-2374.

595 Dobson, F.S. 1990. Environmental effects on infanticide in Columbian ground 596 squirrels. Ethology 84:3-14.

597 Dobson, F.S. 1992. Body mass, structural size, and life-history patterns of the

598 Columbian ground squirrel. American Naturalist 140:109-125.

599 Dobson, F.S., M.J. BADRY, AND C. GEDDES. 1992. Seasonal activity in the Columbian

600 ground squirrel. Canadian Journal of Zoology 70:1364-1368.

601 Dobson, F.S., AND J.D. KJELgaARD. 1985a. The influence of food resources on

602 population dynamics in Columbian ground squirrels. Canadian Journal of

$603 \quad$ Zoology 63:2095-2104.

604 Dobson, F.S., AND J.D. KJElgaARD. 1985b. The influence of food resources on life 605 history in Columbian ground squirrels. Canadian Journal of Zoology 63:21056062109.

607 Dobson, F.S. AND J.O. MURIE. 1987. Interpretation of intraspecific life history patterns:

608 evidence from Columbian ground squirrels. American Naturalist. 129:382-397.

609 Dobson, F.S., AND M.K. OLI. 2001. The demographic basis of population regulation in

610 Columbian ground squirrels. American Naturalist 158:236-247.

611 Dobson, F.S, AND M.K. OLI. 2008. The life histories of Orders of mammals: fast and 612 slow breeding. Current Science 95:862-865. 
613 Dobson, F.S., V.A. Viblanc, C.A. Arnaud, And J.O. Murie. 2012. Kin selection in 614 Columbian ground squirrels: direct and indirect fitness benefits. Molecular $615 \quad$ Ecology 21:524-531.

616 GRAFEN, A. 1988. On uses of data on lifetime reproductive success. In: Reproductive 617 Success, pp. 454-471, T.H Clutton-Brock (ed.) University of Chicago Press, $618 \quad$ Chicago, Illinois.

619 HARE, J.F., AND J.O. MuRIE. 1992. Manipulation of litter size reveals no cost of 620 reproduction in Columbian ground squirrels. Journal of Mammalogy 73:449-454.

621 HinkLeY, D.V. 1969. On the ratio of two correlated normal random variables.

$622 \quad$ Biometrika 3:635-639.

623 Jensen, H., B.-E. SÆTher, T.H. Ringsby, J. Tufto, S.C. GRIFfith, AND H. ElLEgREN.

624 2004. Lifetime reproductive success in relation to morphology in the house 625 sparrow Passer domesticus. Journal of Animal Ecology 73:599-611.

626 Kosova, G., M. ABney, AND C. OBer. 2010. Heritability of reproductive fitness traits 627 in a human population. Proceedings of the National Academy of the U.S.A. $628 \quad 107: 1772-1778$.

629 LANDE, R., AND S.J. ARNOLD. 1983. The measurements of selection on correlated $630 \quad$ characters. Evolution 37:1210-1226.

631 LESLIE, P.H. 1945. On the use of matrices in certain population mathematics. 632 Biometrika 33:183-212.

633 LEWONTIN, R.C. 1965. Selection for colonizing ability. pp. 77-94. In The genetics of 634 colonizing species. H.G Baker and G.L Stebbins (eds.) Academic Press, New $635 \quad$ York, New York. 
636 Maron, J.L., D.E. Pearson, AND R. J. FlethCER, JR. 2010. Counterintuitive effects of

637 large-scale predator removal on a midlatitude rodent community. Ecology

$638 \quad 91: 3719-3728$.

639 McGraw, J.B, AND H. CASwELL. 1996. Estimation of individual fitness from life-

640 history data. American Naturalis 147:47-64.

641 Mcloughlin, P. D., J.-M. Gaillard, M.S. Boyce, C. Bonenfant, F. Messier, P.

642 Duncan, D. Delorme, S. SÄID, S., AND F. KleIN. 2007. Lifetime reproductive

643 success and composition of the home range in a large herbivore. Ecology

$644 \quad 88: 3192-3201$.

645 MeAts, A. 1971. The relative importance to population increase of fluctuations in

646 mortality, fecundity and the time variables of the reproductive schedule.

$647 \quad$ Oecologia 6:223-237.

648 Merilä, J., AND B.C. SHELDON. 2000. Lifetime reproductive success and heritability in

649 nature. American Naturalist 155:301-310.

650 Miyatake, T. 1997. Genetic trade-off between early fecundity and longevity in

651 Bactrocera cucurbitae (Diptera: Tephritidae). Heredity 78:93-100.

652 MURIE, J.O. 1995. Mating behavior of Columbian ground squirrels. 1. Multiple mating

653 by females and multiple paternity. Canadian Journal of Zoology 73:1819-1926.

654 MurIE, J.O., AND D.A. BOAG. 1984. The relationship of body weight to overwinter

655 survival in Columbian ground squirrels. Journal of Mammalogy 65:688-690.

656 MURIE, J.O., AND F.S. DobSON. 1987. The costs of reproduction in columbian ground 657 squirrels. Oecologia 73:1-6. 
658 MURIE, J.O., AND M.A. HARRIS. 1982. Annual variation of spring emergence and 659 breeding in Columbian ground squirrels (Spermophilus columbianus). Journal of $660 \quad$ Mammalogy 63:431-439.

661 Neuhaus, P., D.R. Broussard, J.O. Murie, and F.S. Dobson. 2004. Age of 662 primiparity and implications of early reproduction on life history in female 663 Columbian ground squirrels. Journal of Animal Ecology 73:36-43.

664 Newton, I. (ed.). 1989. Lifetime Reproduction in Birds. Academic Press, London. 665 NeuHaus, P. 2000. Weight comparisons and litter size manipulation in Columbian 666 ground squirrels (Spermophilus columbianus) show evidence of costs of 667 reproduction. Behavioral Ecology and Sociobiology 48:75-83.

668 Neuhaus, P., D.R. Broussard, J.O. Murie, and F.S. Dobson. 2004. Age of 669 primiparity and implications of early reproduction on life history in female 670 Columbian ground squirrels. Journal of Animal Ecology 73:36-43.

671 Oli, M.K., AND K.B. ARmitage. 2003. Sociality and individual fitness in yellow-bellied 672 marmots: insights from a long-term study (1962-2001). Oecologia 136:543-50.

673 Oli, M.K., AND K.B. ARMitaGe. 2008. Indirect fitness benefits do not compensate for 674 the loss of direct fitness in yellow-bellied marmots. Journal of Mammalogy $675 \quad 89: 874-881$.

676 Oli, M. K., AND F.S. Dobson. 1999. Population cycles in small mammals: the role of 677 age at sexual maturity. Oikos 86:557-565.

678 Oli, M.K., AND F.S. Dobson. 2003. The relative importance of life-history variables to 679 population growth rate in mammals: Cole's prediction revisited. The American $680 \quad$ Naturalist 161:422-440 
681 Oli, M. K., G.R. HePP, And R.A. Kennamer. 2002. Fitness consequences of delayed 682 maturity in female wood ducks. Evolutionary Ecology Research 4:563-576.

683 Oli, M.K., N.A. Slade, And F.S. DobSOn. 2001. The effect of density reduction on

684 Uinta ground squirrel populations: an analysis of life table response experiments. $685 \quad$ Ecology 82:1921-1929.

686 Raveh, S., D. Heg, F.S. Dobson, D.W. Coltman, J.C. Gorrell, A. Balmer, and P. 687 NeUHAUS. 2010. Mating order and reproductive success in male Columbian 688 ground squirrels (Urocitellus columbianus). Behavioral Ecology 21:537-547. 689 Raveh, S., D. Heg, V.A. Viblanc, D.W. Coltman, J.C. Gorrell, F.S. Dobson, A 690 BALMER, AND P. NeuHAus. 2011. Male reproductive tactics to increase 691 paternity in the polygynandrous Columbian ground squirrel (Urocitellus 692 columbianus). Behavioral Ecology \& Sociobiology 65:695-706.

693 Reid, J.M., P. Neitlisbach, M.E. Wolak, L.F. Keller, And P. ArCese. 2019.

694 Individuals' expected genetic contributions to future generations, reproductive 695 value, and short-term metrics of fitness in free-living song sparrows (Melospiza 696 melodia). Evolution Letters 3:271-285.

697 REZNICK, D. 1985. Costs of reproduction: an evaluation of the empirical evidence. $698 \quad$ Oikos 44:257-267.

699 RofF, D.A. 1992. The Evolution of Life Histories: Theory and Analysis. Chapman and $700 \quad$ Hall, New York.

701 RofF, D.A. 1996. The evolution of genetic correlations: an analysis of patterns.

$702 \quad$ Evolution 50:1392-1403. 
703 Rubach, K., M. Wu, A. Abebe, F.S. Dobson, J.O. Murie, and V.A. Viblanc. 2016.

$704 \quad$ Testing the reproductive and somatic trade-off in female Columbian ground

$705 \quad$ squirrels. Ecology and Evolution doi:10.1002/ece3.2215.

706 SÆTher, B.-E, AND S. ENGEN. 2015. The concept of fitness in fluctuating environments.

707 Trends in Ecology \& Evolution 30:273-281.

708 Sibly, R., AND P. CALOW. 1986. Why breeding earlier is always worthwhile. Journal of $709 \quad$ theoretical Biology 123:311-319.

710 SkIBIEL, A.L., J.R. SPEAKMAN, AND W.R. Hood. 2013. Testing the predictions of

711 energy allocation decisions in the evolution of life-history trade-offs. Functional

$712 \quad$ Ecology 27:1382-1391.

713 StEarns, S.C. 1992. The Evolution of Life Histories. Oxford University Press, London $714 \quad$ Xii + 249 Pp.

715 Viblanc, V.A., C.M. Arnaud, F.S. Dobson, And J.O. Murie. 2010. Kin selection in

716 Columbian ground squirrels (Urocitellus columbianus): littermate kin provide

717 individual fitness benefits. Proceedings of the Royal Society of London B,

$718 \quad$ Biological Sciences 277:989-994.

719 WigGETT, D.R., AND D.A. BoAG. 1989. Intercolony natal dispersal in the Columbian

720 ground squirrel. Canadian Journal of Zoology 67:42-50.

721 WiLLIAMS, G.C. 1966. Natural selection, the costs of reproduction, and a refinement of

722 Lack's principle. The American Naturalist 100:687-690. 


\section{Figures}

725 Fig. 1. - Spring population size of females in a colony of female Columbian ground

726 squirrels ( $\geq 1$ year old) in Sheep River Provincial Park, Alberta Canada from 1992-2018.

728 Fig. 2. - Regression of individual lambda $\left(\lambda_{\text {ind }}\right)$ on finite population growth $\left(\lambda_{\text {Leslie }}\right)$

729 during the lifetimes of individual females, for three ages at which females first

730 reproduced (ages 1, 2, and 3 and above). a) Fecundity was based on the number of

731 offspring at weaning. b) Fecundity was based on the number of these offspring that

732 survived to emerge from hibernation as yearlings.

734 Fig. 3. - Fitness estimate for females that first reproduced at different ages, from mean

735 relative fitness with standard errors for: a) fecundity estimated from number of offspring

736 at weaning, and b) fecundity estimated from number of offspring that survive their first

737 hibernation to become yearlings. Fitness estimate for females that first reproduced at

738 different ages, from mean lifetime reproductive success with standard errors for: c)

739 lifetime reproductive success based on weaned offspring, and d) lifetime reproductive

740 success based on numbers of yearling offspring.

742 Fig. 4. - Selection on age at first reproduction from regression of fitness (estimated by

743 relative fitness) on age at which females first reproduced (ages 1 through 5), where

744 fecundity was estimated by either a) number of weaned offspring or b) number of

745 surviving yearling offspring. The black line shows the linear least-squares best fit, and

746 the gray line in a) shows the quadratic best fit. 